Brit. J. industr. Med., 1960, 17, 190.

\title{
A STUDY ON THE ACUTE TOXICITY OF THE TRI-ARYL PHOSPHATES USED AS PLASTICIZERS
}

\author{
BY \\ H. F. BONDY,* E. J. FIELD, $\uparrow$ A. N. WORDEN, $\ddagger$ and J. P. W. HUGHES $\S$
}

(RECEIVED FOR PUBlication AUgust 29, 1959)

Paralysis in man and the domestic fowl caused by "ToCP" (tri-cresyl phosphate, tri-tolyl phosphate or TTP) is reviewed, and the search for a non-toxic plasticizer derived either from TTP or tri-xylenyl phosphate (tri-dimethylphenyl phosphate or TXP) is described. It had been previously shown that the ortho-tolyl esters are toxic but we found that their removal does not make the mixture non-toxic. The meta- and para-tolyl esters were known to be free from toxic effects and the 2:4 and 2:5 dimethylphenyl esters were equally shown to be non-toxic except in massive doses. We confirmed that the tri-ortho-ethylphenyl ester was non-toxic, but found the mono- and di-ortho-ethylphenyl phosphates to be highly toxic. We showed that TTP made from phenols with all the ortho-cresol and ortho-ethylphenol removed is non-toxic.

With TXP, however, elimination of all ortho-cresol and ortho-ethylphenol from the raw materials does not result in a non-toxic plasticizer. Tri-ortho- $n$-propylphenyl phosphate was shown to be non-toxic but esters containing one or two ortho-propylphenyl groups are toxic.

The toxicity of the ortho-tolyl, ortho-ethylphenyl and ortho-propylphenyl groups is much reduced in the presence of the $3: 5$-dimethylphenyl group. This influence is greatest in mono-ortho-propylphenyl-di-3 : 5-dimethylphenyl phosphate which is non-toxic in five consecutive daily doses of $500 \mathrm{mg} / \mathrm{kg}$. body weight.

The removal of all ortho-cresol, ortho-ethylphenol and ortho-propylphenol from the raw material results in a non-toxic product which we termed non-toxic plasticizer "NTP". This has been fed in various doses to a variety of mammals and a large number of chickens in short term tests without toxic effects.

Our experiments showed that tri-meta-ethylphenyl phosphate is non-toxic but tri-paraethylphenyl phosphate is highly toxic. The mixture from which NTP is made contains $10 \%$ of para-ethylphenol. Based on chemical statistics the tri-para-ethylphenyl ester can be present only in minute quantities, and we have shown that esters containing one or two para-ethylphenyl groups are non-toxic. An ester with a methyl group in the ortho, and an ethyl group in the para position in the same benzene nucleus (tri-2-methyl-4-ethylphenyl phosphate) we showed, surprisingly, to be non-toxic.

Two aryl phosphate plasticizers are available commercially: tri-tolyl phosphate (TTP) which was formerly known as tri-cresyl phosphate (TCP), and tri-xylenyl phosphate (TXP). They are widely used because of their technical advantages. A plasticizer as well as making a substance more pliable may confer other desirable properties, for example, flame, abrasion and water resistance, and hardness.

*Coalite and Chemical Products Limited.

+ Department of Pathology, University of Durham.

$\ddagger$ Nutritional Research Unit, Huntingdon.

§Albright and Wilson Ltd.
Unfortunately both TTP and TXP are too toxic to be used in connexion with the packaging of food; nor, since they are readily absorbed through the intact skin (Hodge and Sterner, 1943), can they be used for materials in contact with the human body.

The technical advantages of phosphate plasticizers made it worthwhile to aim at preparing one free from toxic effects. In the course of our investigations new light has been thrown on the complicated story of the toxicity of aryl phosphate esters which it is the purpose of this paper to describe. 
Phosphate Plasticizers

Tri-ortho-tolyl Phosphate (Tri-ortho-methylphenyl Phosphate).--Susser and Stein (1957) have reviewed in the literature the history of nine outbreaks of "ToCP" poisoning, including their own series. By far the largest outbreak was that in the U.S.A. in 1930 when 15,000 persons were affected by the adulteration of an alcoholic drink called Jamaica Ginger or Jake by $2 \%$ "ToCP". Most outbreaks have occurred by mixed esters being added intentionally or otherwise to food, and as abortifacients. Hunter, Perry, and Evans (1944) described three cases of industrial poisoning in England in 1942. A recent outbreak affecting 10,000 persons in Morocco was investigated by Smith and Spalding (1959).

In man the illness may start with early transient and indefinite gastro-intestinal symptoms with nausea, vomiting and diarrhoea. After about 10 days, aching and tenderness of the lower leg muscles and numbness of the toes develop, followed by paraesthesiae and loss of superficial sensation of stocking-and-glove distribution. The disturbance of sensation decreases after a few days and weakness supervenes with foot drop. Later the hands are usually affected. The victims can be identified by their high stepping gait (Smith and Spalding, 1959). The paralysis rarely extends beyond knee and elbow, and the effect passes off in the reverse order; the hands may recover completely but permanent foot drop may remain. Whilst the mortality is very low (only 10 persons in 15,000 were reported to have died in the outbreak in the U.S.A.), the paralysis is often permanent. Zeligs (1938) found that in a group of over 300 persons approximately a fifth were still in institutions six years later. In these cases the flaccid paralysis had changed to a spastic type with adductor spasm, paralytic talipes, exaggerated tendon reflexes and extensor plantar responses.

Smith, Elvove, and Frazier (1930) found that the symptom complex of ginger paralysis could be reproduced in some species of laboratory animals by the administration of the phosphoric ester of ortho-cresol. The symptom complex was characterized for the most part by bilateral and symmetrical flaccid paralysis of the distal muscles of the lower, and to a lesser extent of the upper, extremities with little or no sensory disturbance. Smith, Elvove, Valaer, Frazier, and Mallory (1930) in a previous report drew attention to the insensitivity of the dog and the monkey to this poison. This was later explained by incomplete absorption, but even when administered parenterally the same symptom complex was not reproduced in the monkey.

The rat is also highly resistant and oral and subcutaneous doses of up to $30,000 \mathrm{mg}$. $/ \mathrm{kg}$. body weight in two doses of $15 \mathrm{~g}$. each had no effect; but intravenously the $\mathrm{LD}_{50}$ lies between 500 and $1,000 \mathrm{mg} . / \mathrm{kg}$. body weight (Smith et al., 1930). These authors showed that the chicken is the most useful experimental animal as it is very sensitive to the aryl phosphates and suffers effects very similar to those in man. Whether administered in doses just sufficient to produce paralysis or as much as 10 times the minimum paralysing dose the result is nearly the same, except for a difference in degree. For eight to 15 days after administration the animal is healthy but after an interval which rarely extends to 30 days the bird becomes ataxic and unsteady. Within a few days the bird cannot get off its haunches, may fall over and paralysis of the wings begins. With small doses the paralysis is partial and full or partial recovery may occur in two to three months. With larger doses the paralysis extends and after some weeks dyspnoea supervenes. This may last for days or weeks until the animal finally dies. The intravenous minimal paralysing dose is not greatly different from the oral, showing that the chicken absorbs the ester virtually completely. Nor is the latent interval altered by the route of administration. Smith, Engel, and Stohlman (1932) were also the first to show that the daily ingestion of very small, and in themselves, ineffective doses, of tri-ortho-tolyl phosphate over a period of days gives rise to flaccid paralysis; as little as $5 \mathrm{mg} . / \mathrm{kg}$. body weight daily produces the syndrome.

The histopathology was first described by Smith and Lillie (1931). The lesions due to tri-ortho-tolyl phosphate were shown to be mainly in the lumbar and cervical portions of the spinal cord. Cavanagh (1954) states that degeneration of axis cylinders and myelin sheaths is found in both the peripheral nerves and long tracts of the spinal cord, affecting the distal extremities of the axons. Long fibres of large diameter are particularly selected by $\mathrm{ToCP}$. It was these regions which received our attention when one of us (E.J.F.) undertook the histology of animals dosed with a series of chemicals to be described in the development of a non-toxic plasticizer.

Tri-meta-tolyl Phosphate and tri-para-tolyl Phosphate.-Smith et al. (1930) showed that the tri-metatolyl and the tri-para-tolyl phosphates were nontoxic. Hunter et al. (1944) confirmed the lack of toxicity of the para-tolyl ester but found that the meta-tolyl, although not as toxic as the ortho-tolyl was still toxic: cockerels, 12 weeks old, showed weakness of the legs after receiving $12.5 \mathrm{~g}$. of trimeta-tolyl phosphate. Aldridge (1954), Hine, Dunlap, Rice, Coursey, Gross, and Anderson (1956) and Henschler (1958), on the other hand, have shown that if a phosphate ester is made from pure meta- 
cresol, pure para-cresol or a mixture of the two, the resulting ester is non toxic. We have confirmed these results in our own series, finding both the trimeta-tolyl and para-tolyl phosphates non-toxic to chickens, and it appears likely that Hunter's metatolyl ester must have been adulterated with one of the ortho-tolyl esters.

Commercial tri-tolyl Phosphate.-For many years this material has been made from a phenolic fraction containing ortho-, meta- and para-cresols and xylenols. This fraction is reacted with phosphorus oxychloride and a number of esters is formed which contain not only the symmetrical tri-esters but mixed esters as well. Tri-ortho-tolyl phosphate is one of the esters present in commercial TTP and as it was considered that the toxicity of TTP was solely dependent on the amount of $o$-cresol present in the raw material from which the esters are made, some countries demand that any cresol fraction used in the preparation of TTP should contain not more than $3 \%$ ortho-cresol. This provision has indeed reduced, but equally has by no means abolished, the toxicity of commercial TTP. Barnes (1958) and Henschler (1958) have shown that a mixed ester which contains either one or two ortho-tolyl groups in the molecule is more toxic than tri-ortho-tolyl phosphate itself. Henschler (1958) found that a TTP made from raw material containing $30 \%$ orthocresol is 10 times as toxic as one made from pure ortho-cresol, and that an ester with one orthogroup is much more toxic than one which contains three ortho-groups, with the di-ortho compounds intermediate in toxicity. This means that an analysis must include all the mixed esters that can be formed from the various phenols in the mixture. The fact that a tri-substituted ester could be non toxic but a mono-substituted ester with the same phenol could be toxic meant that a more detailed analysis was needed. At first sight the demonstration that tri-o-ethylphenyl phosphate was not toxic (see below) might have led to the assumption that $o$-ethylphenol could safely be left in the raw materials. It is important to remember that monosubstituted esters are those most likely to be formed by impurities.

An ester made from meta- or para-cresol has the same technical advantages as TTP or TXP, but the isolation and high degree of purification of the metaand para-cresol in the first instance makes the cost commercially prohibitive. We therefore decided to attempt the purification of the commercial raw material used in the production of TTP and TXP; and, as a first step, we isolated the component phenols and tested the toxicity of their phosphate esters. This work has been in progress since 1956.

\section{Materials and Methods}

Preparation of Esters. *-The phosphate tri-esters were prepared by reacting $1 \mathrm{~mol}$. of phosphorus oxychloride with $3 \mathrm{~mol}$. of the phenolic material and the resulting ester was purified by fractional distillation under high vacuum. The impurities were isolated and identified.

The general method used for the preparation of the mixed esters consisted of reacting the first phenol $(2 \mathrm{~mol}$.) with phosphorus oxychloride $(1 \mathrm{~mol}$.) to give the diaryl phosphorochloridate. This material was rigorously purified by fractional distillation and its purity checked by analysis; it was then reacted with the second phenol in alkaline solution under Schotten-Baumann conditions. The resulting mixed ester was purified by distillation under very high vacuum (taking great care to avoid any disproportionation) and by recrystallization when possible.

Three groups of phosphate esters were used: (1) pure tri-esters, (2) mixed esters from two phenols of definite chemical composition and (3) phosphate esters from a mixture of phenols. Their formation and properties are given in Tables 1,2 , and 3 . With regard to esters from a mixture of phenols it is not possible to give an analysis of the esters themselves, but a composition of the phenolic material is given which has been evaluated by fractional distillation and infra-red analysis. All the phosphate esters used were purified by fractional distillation under high vacuum. Solid phosphate esters were recrystallized to a constant melting point. All the mixed esters were analysed for carbon, hydrogen and phosphorus $\dagger$.

Further details about the chemical preparations and their purification will be published elsewhere.

Animals.-Fowls were mainly Light Sussex X Rhode Island Red or White Leghorn X Light Sussex, of both sexes, obtained from the Houghton Poultry Research. Station. For a limited number of experiments, advantage was taken of the availability of Incross chickens produced at the National Poultry Institute Northern Breeding Station, Reaseheath, Cheshire (Clough and Cock, 1957). Barnes and Denz (1953) have shown that young birds at the time of administration of di-isopropyl fluorophosphate (DFP) may fail to develop characteristic signs or lesions. To check this age factor preliminary experiments, each involving a group of 10 Incross chickens, showed that a single oral dose of $1,000 \mathrm{mg}$. $/ \mathrm{kg}$. body weight of ToCP was without effect when administered at 10,20,30,40 or 50 days of age, but neurotoxic when administered at 72 or 100 days of age. The birds dosed at up to 50 days were subsequently maintained alive for a year, but none developed symptoms. Later we took 100 days of age as a minimum in all our toxicity testing in chickens except in cases where we brought young birds up on a diet containing an aryl phosphate plasticizer so that they became accustomed to this oily solution in their food. All birds were maintained on the premises for not less

\footnotetext{
* The isolation and identification of single phenols from phenolic fractions was carried out by J. Gumb. The synthetic phenols and the phosphate esters were prepared by A. Gregory. Both are members of the Research Department of Coalite and Chemical Products Limited.

tThe phosphorus analyses were done by C. R. Kennedy of the Medical Research Council's Toxicology Research Unit.
} 
than 14 days prior to dosing, with checks on body weight and on the excretion of coccidial öocysts in the faeces. Any birds that were suspected to be ailing, or to have died from a non-specific cause, were subjected to detailed examination at the Houghton Poultry Research Station.

Administration and Dosing.-Oral dosing, except where otherwise stated, was given with the test substance in arachis oil or in an emulsion comprising arachis oil 10 parts, gum acacia 3 parts and water 10 parts, and administered by stomach tube. During the course of our toxicity testing we discovered that, while birds might be unaffected by a single dose of $2,500 \mathrm{mg} . / \mathrm{kg}$. body weight, an ester might prove toxic in five consecutive daily doses of $500 \mathrm{mg} . / \mathrm{kg}$. body weight.

Smith et al. (1930) had found that a single dose of $50 \mathrm{mg}$. of $\mathrm{ToCP} / \mathrm{kg}$. body weight, or repeated doses of $5 \mathrm{mg} . / \mathrm{kg}$. body weight, caused paralysis. We regarded 50 times the dose level proposed by Smith et al. (1930) (i.e., five doses of $500 \mathrm{mg} . / \mathrm{kg}$. body weight) as an appropriate level at which to determine whether our aryl phosphate was toxic or not. In many tests much larger doses were given, sometimes up to 500 times Smith's dosing.

\section{Diagnostic Procedures}

Clinical Observations.-The effects of test doses were studied by clinical observation and routine weighings. After the administration of tri-tolyl phosphate, which is known to be toxic to chickens, there is a steady deterioration in weight. The earliest nervous damage noted is observed usually about the eighth or tenth day after the initial dose when the birds tend to squat unless they are disturbed. The birds have a high stepping gait of a tabetic character and are clumsy, particularly after exercise; in addition there is unsteadiness on landing after flight. Whilst standing still the hocks turn in unequally and the feet are spread widely to maintain balance.

Muscular incoordination becomes progressively worse over the next four to five days, paralysis supervenes on the ataxia, and birds sink on to their hocks whilst attempting to run. The weakness is most apparent in the legs; the wings are still capable of strong action at this stage. Unless the dosage has been heavy, recovery may start at this point. The signs of ataxia and paralysis pass off in the reverse order. With heavier doses the paralysis progresses with continuing loss of weight until the birds are helpless, with legs extended forward from the hip joint and the wings drooping, but some movement in the wings is possible until death. Birds in this stage are weakened by starvation and die from inanition.

The dosage level is of some importance in the degree of ataxia and paralysis caused; but there is a critical dose, remarkably constant at about $50 \mathrm{mg}$. $/ \mathrm{kg}$. body weight with TTP, where some nervous damage always occurs in chickens. This critical level of dosage is also independent of its administration as one single dose, or in divided portions over days. Neurological signs are not, however, advanced by increasing the dosage.

Cholinesterase Determinations.-Plasma cholinesterase was determined with a Warburg respirometer by the method of Ammon (1933). Total and pseudo cholinesterase in brain were determined by the method of Earl and Thompson (1952) and with a Warburg respirometer.

Pathological Examination.-Animals for post-mortem examination were killed by exsanguination under anaesthesia. Material for histological examination was fixed in $10 \%$ formol. In our hands preparations fixed by perfusion showed no significant advantage for Marchi staining over those fixed by immersion so that after preliminary trials the latter method was uniformly used. The brain, after removal, was fixed for 48 hours before being sectioned. Complete laminectomy was performed to allow free access of fixative to the cord for 36 to 48 hours. Following this the cervical, thoracic, and lumbosacral portions of the cord were dissected out. The lumbosacral portion included the glycogen body. Paraffin sections of the brain at pituitary level, the medulla and at various cord levels were prepared and stained by Giemsa's stain and haematoxylin and eosin.

Pieces of cervical, thoracic, and lumbosacral cord 1-2 mm. thick, and carefully cleaned $2 \mathrm{~cm}$. lengths of upper and lower sciatic nerve were impregnated by the method of Poirier, Ayotte, and Gauthier (1954), in their modification of Swank and Davenport's (1935) adaptation of the Marchi method.

Histological Findings. - The Marchi preparations occasionally showed artefacts which could be readily recognized and were present equally in dosed and undosed birds. But when a toxic material, for example tri-orthotolyl phosphate was given, demyelination was massive and most prominent in the lumbar sections of the cord, except in cases of long standing when the cervical region showed equal or even greater demyelination. The brain and spinal cord had normal nerve cells and the appearance in the sciatic nerves was variable, but some demyelination was usually present. Some birds showed many degenerated fibres with light brown myelin droplets alongside fully blackened ones.

\section{Results}

Tri-tolyl Phosphate (o-cresol removed from the Phenolic Fraction).-The raw material contained the phenols given in Table 1. By careful fractionation of a cresol fraction the $o$-cresol was removed (Table 1) and the remainder reacted with $\mathrm{POCl}_{3}$ and the ester formed. This ester was given in two consecutive daily doses of $250 \mathrm{mg}$. $/ \mathrm{kg}$. body weight to two chickens and both birds became ataxic. This was repeated on another six chickens which were given two daily doses of $500 \mathrm{mg}$. $/ \mathrm{kg}$. body weight, and, of the group, five became paralysed. One of these on histological examination showed demyelination.

At this time it was considered that the raw material contained only meta-cresol, para-cresol, $2: 4$ and $2: 5$-dimethylphenol. Many workers, including ourselves, have shown that the phosphates of the meta- and para-cresols are non-toxic. One 
TABLE 1

PERCENTAGE COMPOSITION OF PHENOLIC FRACTIONS USED TO MAKE PHOSPHATE ESTERS

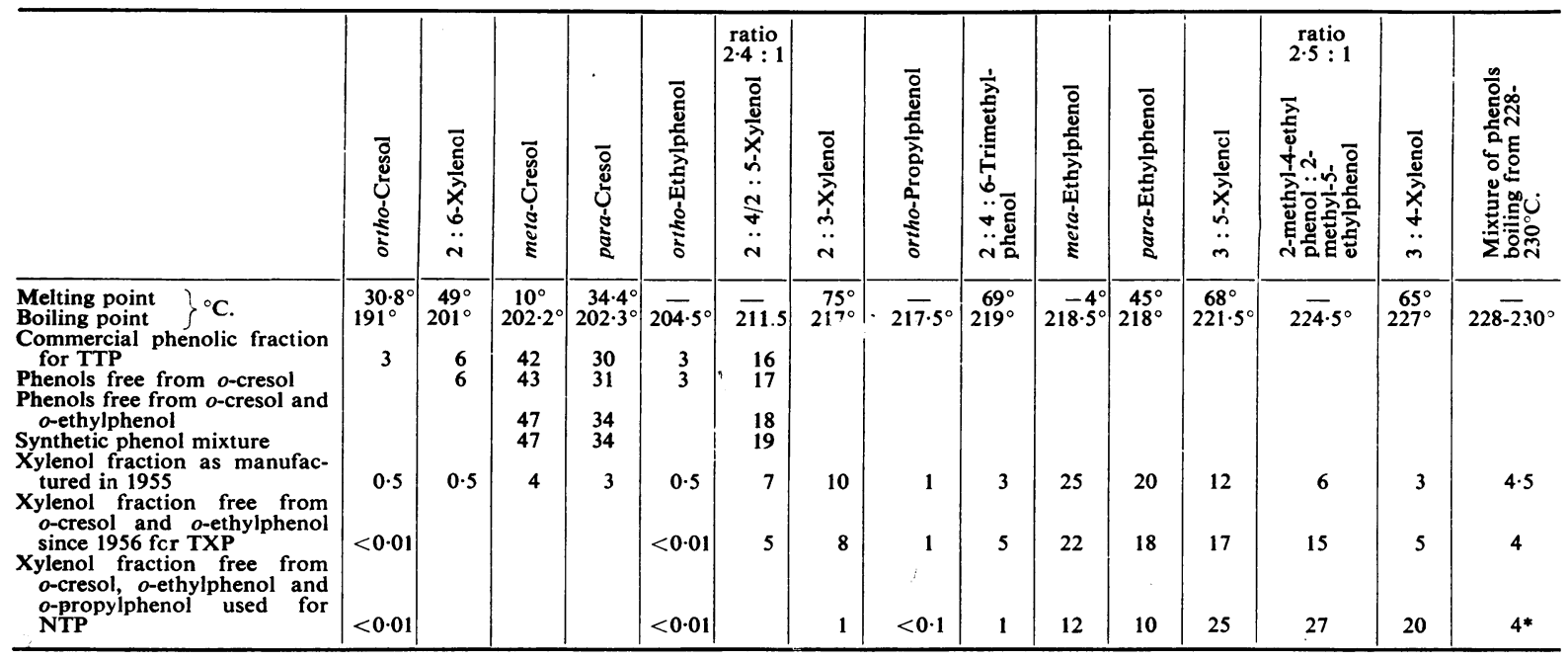

*This fraction consists of a mixture of the following phenols: 2 : 6-dimethyl-4-ethylphenol, 2-methyl-3-ethylphenol, 2 : 3 : 5-trimethylphenol, meta-propylphenol, para-propylphenol.

chicken, dosed with a single dose of $2,500 \mathrm{mg} . / \mathrm{kg}$. body weight of tri-meta-tolyl phosphate, remained healthy in all respects and increased in weight. Three birds given similar single doses of tri-paratolyl phosphate also had no signs of any kind and two of the three gained weight. From these observations we assumed that the $2: 4$ and $2: 5$-dimethylphenols must be the toxic element so we prepared tri-2:4, $2: 5$ dimethylphenyl phosphate free from ortho, meta and para tolyl and ortho-propylphenyl esters, which was given in five consecutive daily doses of $500 \mathrm{mg} . / \mathrm{kg}$. body weight (total $2,500 \mathrm{mg}$.) to six chickens. But the birds remained healthy in all respects. This is in agreement with other workers who have studied the tri-xylenyl phosphates. On the other hand Henschler and Bayer (1958) found that two of the six xylenyl phosphates tested produced some ataxia in very large doses $(1,000 \mathrm{mg} . / \mathrm{kg}$. body weight daily for $\mathbf{4 0}$ days). Although we found the esters from $2: 6,2: 4,2: 5,2: 3,3: 5$ and $3: 4$-xylenols to be non-toxic when given in doses of $5 \times 500 \mathrm{mg}$. $/ \mathrm{kg}$. body weight, we repeated the work of Henschler and Bayer with tri-2:3-xylenyl phosphate at their dose level and found that the birds became paralysed. Nevertheless the toxicity of TTP minus the ortho-tolyl esters could not be accounted for by the presence of $2: 4$ and $2: 5$ dimethylphenyl esters, when given in doses of $5 \times 500 \mathrm{mg}$. $/ \mathrm{kg}$. body weight.

Tri-ortho-ethylphenyl Phosphate.-After the removal of $o$-cresol there remained $3 \%$ o-ethylphenol
(Table 1). On the basis of the non-toxicity of the xylenol derivatives and the toxicity of ToTP it was assumed that one ortho group was necessary to produce toxic effects and that more than one group on the phenolic ring would prevent toxicity.

In two separate experiments using 10 chickens in each batch, birds were dosed with five consecutive daily doses of $500 \mathrm{mg}$. $/ \mathrm{kg}$. body weight of tri-orthoethylphenyl phosphate $(2,500 \mathrm{mg}$. in all). The birds were unaffected, thus confirming the lack of toxicity of tri-ortho-ethylphenyl phosphate found by Hine et al. (1956). Our first experiments with a less carefully purified material had produced some toxic effects.

\section{We therefore prepared:}

Mono-ortho-ethylphenyl di-para-tolyl Phosphate. -As the phenolic fraction from which the orthocresol was removed contains only $3 \%$ of orthoethylphenol it must be assumed that the phosphate ester will contain only minute quantities of the tri-ester. The ortho-ethylphenyl group will therefore be present in mixed esters, containing one or two ortho-ethylphenyl groups.

Earlier findings show that mixed esters, containing one or two o-tolyl groups are much more toxic than tri-ortho-tolyl phosphate and we considered that the toxicity of TTP containing no orthotolyl ester might be due to the presence of esters containing one or two ortho-ethylphenyl groups.

Mono-ortho-ethylphenyl di-para-tolyl phosphate was synthesized and tested for toxicity. Single doses 
of $1,000 \mathrm{mg} . / \mathrm{kg}$. body weight were given to five birds. All the birds became severely paralysed. Single doses of $250 \mathrm{mg}$. $/ \mathrm{kg}$. body weight given to three birds similarly paralysed them all. In a series of further experiments we showed that a dose of $50 \mathrm{mg}$. $/ \mathrm{kg}$. body weight, whether given as a single dose or as $5 \times 10 \mathrm{mg}$., paralysed all birds.

Di-ortho-ethylphenyl mono-para-tolyl phosphate was also found to be toxic. Three out of four chickens dosed with $5 \times 500 \mathrm{mg}$. $/ \mathrm{kg}$. body weight became paralysed. This was confirmed by Barnes (1958). Two birds dosed by him with $1 \mathrm{ml} / \mathrm{kg}$. body weight became ataxic, whereas two others on $0.2 \mathrm{ml} . / \mathrm{kg}$. showed no effects.

We can therefore state that the toxicity of commercial TTP is due not only to the presence of phosphate esters containing one, two or three ortho tolyl groups but also due to the toxicity of phosphate esters containing one or two ortho-ethylphenyl ,groups.

TTP made from a raw Material (ortho-cresol and ortho-ethylphenol having been Removed).-It is obvious that we had to remove both ortho-ethylphenol and ortho-cresol from the raw material used in the production of TTP. The removal of $o$-ethylphenol is not easy because the boiling points of ortho-ethylphenol and meta-para-cresol are very close and are almost identical if distilled under a vacuum. Although it is not possible to remove the ortho-ethylphenol by fractionation it is more steam volatile than meta- and para-cresol and we attempted its removal by azeotropic distillation with water under vacuum; probably a small amount still remained in the raw material.

The TTP made from this raw material was then fed to two chickens in two consecutive doses of $250 \mathrm{mg}$. $/ \mathrm{kg}$. body weight each, and six further birds were given two doses of $500 \mathrm{mg}$. $/ \mathrm{kg}$. body weight. The birds were unaffected.

We next dosed seven birds with five consecutive doses of $500 \mathrm{mg}$. $/ \mathrm{kg}$. body weight $(2,500 \mathrm{mg}$. $/ \mathrm{kg}$. body weight total dose). Five of the birds became paralysed and one of these was histologically examined and found to have demyelination.

Synthetic Phenol Mixture.-We prepared a mixture containing $47 \%$ meta-cresol, $34 \%$ para-cresol and $19 \% 2: 4,2: 5$-dimethylphenol from pure phenols. These appeared to be the only remaining ingredients in the original phenolic mixture. From this mixture we formed the ester. Twelve birds were given $2,500 \mathrm{mg}$. $/ \mathrm{kg}$. body weight in five consecutive $500 \mathrm{mg}$. daily doses and were not affected. This phosphate ester is therefore non-toxic, indicating that some toxic impurity had remained in the previous preparation. The complete removal of ortho-cresol and ortho-ethylphenol from commercial TTP would be so costly that the resulting TTP would be too expensive, and we therefore turned our attention to trixylenyl phosphate (TXP).

Tri-xylenyl Phosphate.-In 1955, TXP was manufactured from a phenolic fraction (see Table 1) which contained all the xylenols, meta- and paraethylphenol, methylethylphenols and meta- and para-cresol. This material was found to be about one fifth as toxic as TTP. In other words, doses of up to approximately $1,000 \mathrm{mg}$. $/ \mathrm{kg}$. body weight could be given to chickens without clinical effect, but if the dose was increased beyond this, toxic effects became apparent so that it would be necessary to remove some toxic impurity.

TXP from Raw Material minus ortho-cresol and ortho-ethylphenol.-By careful fractionation in the laboratory we prepared a material free from both ortho-cresol and ortho-ethylphenol, as shown in Table 1. The phosphate ester was formed from this new raw material. Thirteen birds were given $1,250 \mathrm{mg} . / \mathrm{kg}$. body weight in two consecutive daily doses of $625 \mathrm{mg}$. No toxic effect was found and histological findings were negative. Later the dose was increased to $5 \times 500 \mathrm{mg}$. $/ \mathrm{kg}$. body weight $(2,500 \mathrm{mg} . / \mathrm{kg}$. total $)$, and four out of 12 birds showed signs of ataxia.

The raw material for the production of TXP was now free of ortho-cresol and ortho-ethylphenol and in consequence the toxicity of the TXP had been reduced to one tenth that of TTP, although we had not succeeded in making a non-toxic tri-xylenyl phosphate.

Ortho-propylphenol.-On the theory that a phenolic compound having one group in the ortho position gives rise to toxic phosphate esters, we examined the phenolic raw materials from which TXP is produced for the presence of ortho-npropylphenol. There is no indication in the literature that coal tar xylenols made from British coal contain ortho- $n$-propylphenol although it has been identified in German coal tar (Steinkopf, 1941).

We found that the xylenol fraction from which TXP is made contains 1 to $1.5 \%$ of ortho-n- propylphenol, hence we decided that the toxicity of phosphate esters containing $n$-propylphenol should be investigated.

Tri-ortho-n-propylphenyl Phosphate.-A supply of $n$-propylphenol was obtained from an outside source and tri-ortho-propylphenyl phosphate was prepared. No clear conclusions about the toxicity of this preparation could be drawn, because the results on chickens were not consistent. We therefore synthesized the $n$-propylphenol and carefully 
TABLE 2

PHYSICAL CONSTANTS AND TOXICITY OF SYMMETRICAL TRI-ARYL PHOSPHATES

\begin{tabular}{|c|c|c|c|}
\hline Compound & $\begin{array}{l}\text { Boiling Point at } \\
1 \mathrm{~mm} . \mathrm{Hg}\left({ }^{\circ} \mathrm{C} .\right)\end{array}$ & $\underset{\left(\mathrm{n}_{\mathrm{D}}{ }^{20}\right)}{\text { Refractive Index }}$ & $\begin{array}{c}\text { Toxicity } \\
\text { (Ataxia in Chickens*) }\end{array}$ \\
\hline $\begin{array}{l}\text { Tri-o-tolyl phosphate } \\
\text { Tri-m-tolyl phosphate } \\
\text { Tri-p-tolyl phosphate } \\
\text { Tri-o-ethylphenyl phosphate } \\
\text { Tri-m-ethylphenyl phosphate } \\
\text { Tri-p-ethylphenyl phosphate } \\
\text { Tri-o-normal propylphenyl phosphate } \\
\text { Tri-(2-methyl-4-ethyl-phenyl) phosphate }\end{array}$ & $\begin{array}{l}207-209^{\circ} \\
\left.224-226^{\circ} \text { (m.p. } 23^{\circ} \mathrm{C} .\right) \\
\left.236 \cdot 5-238 \cdot 5^{\circ} \text { (m.p. } 78 \cdot 5^{\circ} \mathrm{C} .\right) \\
221-223^{\circ} \\
230-232^{\circ} \\
247 \cdot 5-249 \cdot 5^{\circ} \\
247-249^{\circ} \\
265-267^{\circ}\end{array}$ & $\begin{array}{l}1 \cdot 5603 \\
1 \cdot 5568 \\
1 \cdot 5508 \\
1 \cdot 5468 \\
1 \cdot 5480 \\
1 \cdot 5422 \\
1 \cdot 5465\end{array}$ & $\begin{array}{l} \pm \\
\overline{-} \\
\overline{-} \\
\overline{+}\end{array}$ \\
\hline
\end{tabular}

* Ataxia with or without paralysis in chickens within 30 days of dosing with $500 \mathrm{mg}$. $/ \mathrm{kg}$. or higher dose.

purified it. The tri-ortho-propylphenyl phosphate was formed and this also was purified. We gave $5 \times 500 \mathrm{mg}$. $/ \mathrm{kg}$. body weight of this compound to eight birds and all the birds remained healthy. We can, therefore, state that, like tri-ortho-ethylphenyl phosphate, tri-ortho-propylphenyl phosphate is non-toxic.

Mono - ortho - propylphenyl di - para - ethylphenyl Phosphate.-As in the case of $o$-ethylphenol, mixed esters containing one or two ortho-propylphenyl groups might be toxic. Our raw material contained $18 \%$ p-ethylphenol so we synthesized mono-orthopropylphenyl di-para-ethylphenyl phosphate by two different methods, and both preparations were tested for toxicity. In three experiments 12 birds were each given single doses of $1,000 \mathrm{mg} . / \mathrm{kg}$. body weight and all birds were severely paralysed. Another three birds were given single doses of $500 \mathrm{mg} . / \mathrm{kg}$. body weight and all showed ataxia within 12 days after dosing. A further three were given single doses of $100 \mathrm{mg}$. $/ \mathrm{kg}$. body weight and all showed ataxia within 10 days. There was, however, no toxic effect when $50 \mathrm{mg}$. $/ \mathrm{kg}$. body weight was given. This substance is therefore markedly toxic. Di-ortho-propylphenyl mono-paratolyl phosphate was given in two experiments to six birds. Four birds were given $500 \mathrm{mg}$. $/ \mathrm{kg}$. body weight in five consecutive doses and two were given $500 \mathrm{mg}$. $/ \mathrm{kg}$. body weight in four consecutive doses. All birds showed ataxia within 10 days. It is most probable that the slight toxicity of TXP is due to the presence of small amounts of mixed esters containing one ortho-propylphenyl group.

The Effect of 3 :5-dimethylphenol.-Although it was shown that a phosphate ester containing one ortho-propylphenyl group is markedly toxic, this statement must be qualified. Mono-ortho-propylphenyl di-3 : 5-dimethylphenyl phosphate was synthesized and given to five chickens in single doses of $1,000 \mathrm{mg} . / \mathrm{kg}$. bcdy weight. The birds were unaffected by the ester although one developed fowl paralysis. Next, five consecutive daily doses of $500 \mathrm{mg}$. $/ \mathrm{kg}$. body weigh.t were given to three birds all of which remained normal. The conclusion reached is that the 3:5-dimethylphenyl group counteracted the toxicity of the ortho-propylphenyl group.

In order to investigate the effect of the $3: 5$ dimethylphenyl group further, mono-ortho-tolyl-di$3: 5$ dimethylphenyl phosphate and mono-orthoethylphenyl-di-3 : 5-dimethylphenyl phosphate were synthesized. They were tested for toxicity by Barnes (1960). A single dose of 1,000 mg. of mono-ortho - tolyl - di - 3:5-dimethylphenyl phosphate $/ \mathrm{kg}$. body weight was given to two hens, one of which became severely, and the other moderately, ataxic. A dose of $500 \mathrm{mg}$. $/ \mathrm{kg}$. gave rise to no signs in 16 days in a further two birds.

Mono-ortho-ethylphenyl-di-3 : 5-dimethylphenyl phosphate was given in a single dose of $1,000 \mathrm{mg} . / \mathrm{kg}$. body weight to two birds and both became severely paralysed. Half this dose caused mild ataxia in a further bird but no effect in another. It can be concluded that the $3: 5$-dimethylphenyl group reduces the toxicity of the ortho-substituted phenyl groups considerably. Henschler (1959) came to the same conclusion.

Phosphate Ester made from a Xylenol Fraction Free from ortho-cresol, ortho-ethylphenol and orthopropylphenol ("NTP"). - In order to prepare a non-toxic plasticizer it seemed to be necessary to remove from the raw material not only ortho-cresol and ortho-ethylphenol but also ortho-propylphenol.

The raw material for the production of TXP has a boiling range from $215^{\circ}$ to $230^{\circ} \mathrm{C}$. If we could prepare a material by careful fractionation which has a boiling range from $217^{\circ}$ to $230^{\circ} \mathrm{C}$. it would reduce the amount of $o$-propylphenol in the fraction to a very small quantity. (Phenols boiling above $230^{\circ} \mathrm{C}$. were not included in the fraction because they give rise to coloured phosphate esters.) Such a phenolic fraction was prepared first in the laboratory and later on in the plant and is shown in Table 1. This fraction was reacted with phosphorus oxychloride in the presence of a catalyst to form the phosphate ester which is an oily colourless liquid. 
This phosphate ester, subsequently termed "nontoxic plasticizer-NTP", was subjected to a variety of toxicity tests in a large number of animals. Batches from the laboratory and the plant were fed in varying doses, principally to chickens and rats, but also to a number of other animals including the rabbit, which is known to be sensitive to TTP. Table 4 shows that more than 100 chickens have been given doses of NTP ranging between $1,000 \mathrm{mg}$. $/ \mathrm{kg}$. to $25,000 \mathrm{mg}$. $/ \mathrm{kg}$. body weight. Fifteen birds were examined histologically with no abnormal findings. Six chickens were injected intraperitoneally with $1,000 \mathrm{mg}$. $/ \mathrm{kg}$. body weight of NTP without clinical effect. The other animals examined (one dog, rabbit, guinea pig, hamster, four cats and 36 rats) were each given single doses of $5,000 \mathrm{mg}$. $/ \mathrm{kg}$. body weight without detrimental effect. Rats can tolerate $10,000 \mathrm{mg} . / \mathrm{kg}$. body weight without causing any clinical effects.

Cholinesterase estimations of blood and brain were carried out on a variety of animals. In chickens there was an invariable drop of up to $80 \%$ in the plasma cholinesterase in the first 24 hours, which returned to normal over the next few days even when dosing was continued. In rats the plasma cholinesterase was either lowered very slightly by NTP or was unaltered. An account of these investigations by one of us (A.N.W.) is being prepared for publication elsewhere.

Tri-meta- and tri-para-ethylphenyl Phosphate.It has been found previously that the phosphate esters of 3:5-dimethylphenol and 3:4-dimethylphenol are non-toxic, and we decided to test the phosphate esters of the other compounds present in the raw material. From synthetic materials we prepared tri-meta-ethylphenyl phosphate and tripara-ethylphenyl phosphate.

We gave six birds $5 \times 500 \mathrm{mg}$. $/ \mathrm{kg}$. body weight of tri-meta-ethylphenyl phosphate. All the birds remained healthy and two were histologically examined with negative findings. Two birds were given a single dose of $1,000 \mathrm{mg}$. $/ \mathrm{kg}$. body weight with some doubtful effects, but histological examination also gave negative findings. Three further birds were given a single dose of 1,000 $\mathrm{mg} . / \mathrm{kg}$. They remained completely well, two were examined histologically, both with negative results. We concluded that tri-meta-ethylphenyl phosphate is non-toxic.

We dosed 30 birds in several batches with tri-paraethylphenyl phosphate from $5 \times 500 \mathrm{mg}$. $/ \mathrm{kg}$. down to single doses of $200 \mathrm{mg} . / \mathrm{kg}$. body weight. In all cases the birds were paralysed and histological examination confirmed that there was demyelination. This finding is contrary to the working hypothesis we had formed, namely, that only a phosphate ester made from a compound with one substituent group in the ortho position is toxic; in this case a phosphate ester with ethyl groups in the para position is also toxic. This is a surprising finding because a tri-para-tolyl phosphate is definitely not toxic.

Mixed Esters Containing One or Two paraethylphenyl Groups.-We had to reconsider the reasons for the lack of toxicity in the "non-toxic plasticizer". It has been shown that the raw material we prepared for this plasticizer contained $10 \%$ of para-ethylphenol and despite this the phosphate ester was non-toxic. We thought originally that this was due to there not being enough of the phosphate tri-ester of para-ethylphenol present to cause toxicity at the dose level of $2,500 \mathrm{mg} . / \mathrm{kg}$. Birds were therefore dosed with 10 times this dose, namely, $25,000 \mathrm{mg} . / \mathrm{kg}$. body weight but even then no toxic effect was found.

We considered next that in the non-toxic phosphate ester, the tri-para-ethylphenyl phosphate is unlikely to be present, and that the para-ethylphenyl group will only be present in mixed esters having one or possibly two para-ethylphenyl groups attached to the phosphate radical. This was substantiated by the addition of $10 \%$ tri-para-ethylphenyl phosphate to the non-toxic phosphate esters and we found that this mixture became toxic.

We prepared the following esters (see Table 3): mono-para-ethylphenyl di-p-tolyl phosphate was given to 15 birds in the following doses $/ \mathrm{kg}$. body weight. Three birds in each group received $5 \times 500$ mg.; $5 \times 1,000$ mg.; $7 \times 1,000$ mg.; single doses of $2,500 \mathrm{mg}$., and a single dose of $1,000 \mathrm{mg}$. intraperitoneally. One bird died of egg peritonitis and one of lymphomatosis but all the other birds remained well. One of the healthy birds was killed, examined histologically and no demyelination was seen. Post-mortem examinations on the two sick birds revealed the cause in each case.

Mono-para-ethylphenyl di-3 : 5-dimethylphenyl phosphate was given to seven birds. Four received $5 \times 500 \mathrm{mg}$. and three $1,000 \mathrm{mg}$. $/ \mathrm{kg}$. body weight. At this time lymphomatosis occurred in some of the birds and the results did not give a clear picture but post-mortem and histological examinations showed no toxic effects due to the phosphate ester. The experiment was repeated on 12 birds in the following doses $/ \mathrm{kg}$. body weight: three received $5 \times 500 \mathrm{mg}$.; three $4 \times 1,000 \mathrm{mg}$; three $7 \times 1,000 \mathrm{mg}$. and three were injected intraperitoneally with a single dose of $1,000 \mathrm{mg}$. In all cases the birds remained healthy. One bird was examined histologically and found to be normal. 
TABLE 3

PHYSICAL CONSTANTS AND TOXICITY OF UNSYMMETRICAL TRI-ARYL PHOSPHATES

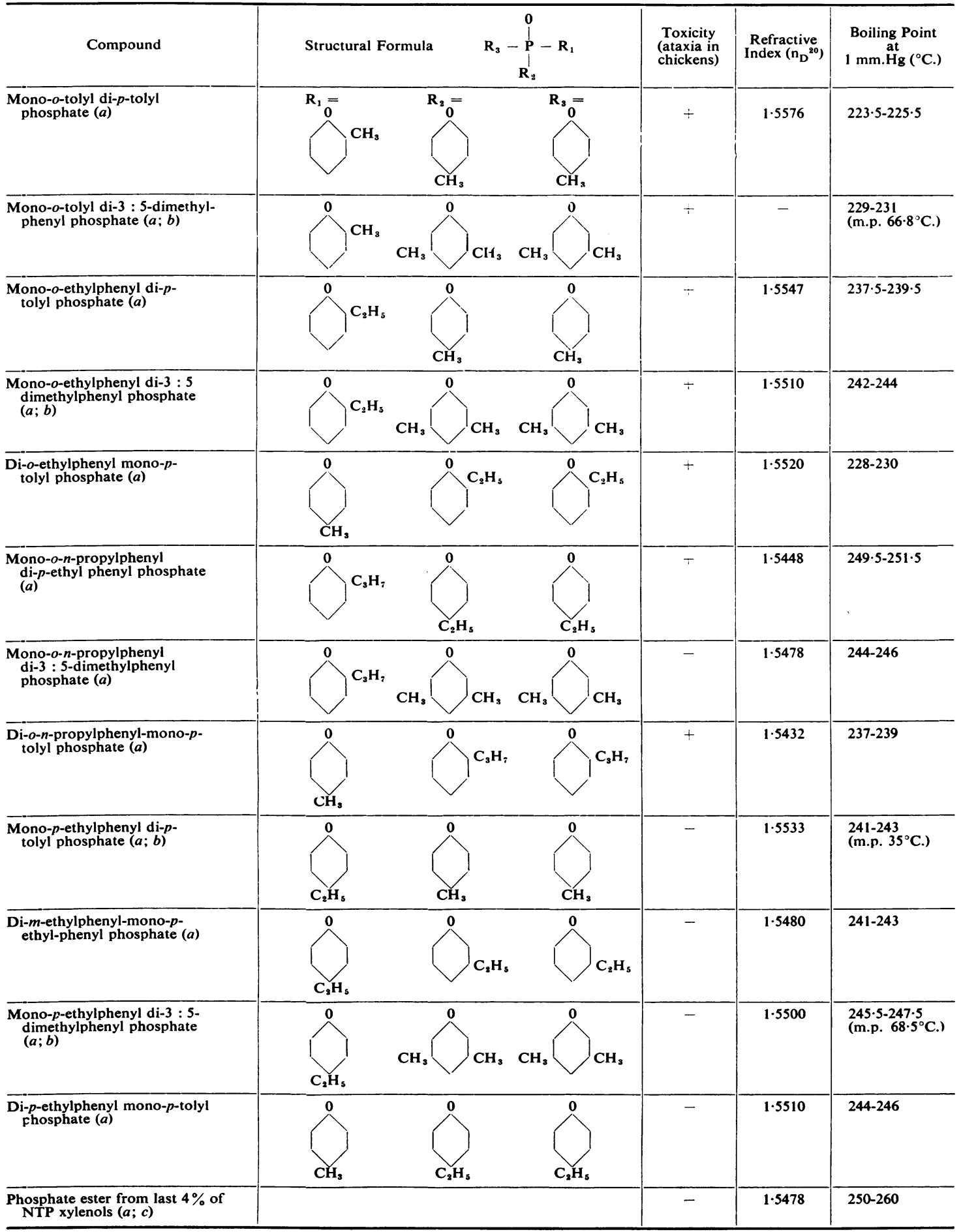

Notes.-(a) Purified by fractional distillation; (b) Recrystallized to constant melting point; (c) Phenolic raw material was the $4 \%$ highest boiling fraction of NTP xylenols.

Other raw materials were as described in Table 2, with the addition of 3, 5-dimethyl phenol $(b), \mathrm{m} . \mathrm{p} .64^{\circ} \mathrm{C}$. 
Di-para-ethylphenyl mono-para-tolyl phosphate was given to four birds at a dose level of $5 \times 500$ $\mathrm{mg} . / \mathrm{kg}$. and four birds received a single dose of $1,000 \mathrm{mg}$. $/ \mathrm{kg}$. body weight. In all cases the birds remained healthy. Similarly we found di-metaethylphenyl mono-para-ethylphenyl phosphate to be non-toxic at this dose level in six birds.

We concluded from these experiments that mixed esters containing one or two para-ethylphenyl groups may be non-toxic, unless ortho-alkylphenyl groups are present in the molecule. Since ortho-cresol, ortho-ethyl phenol and ortho-propylphenol are absent from the starting material, such toxic esters cannot be formed.

Tri-2-methyl-4-ethylphenyl Phosphate.-We tested another compound which is present in the raw material and which is of particular interest because it has an ethyl group in the para position and a methyl group in the ortho position, namely, 2-methyl-4-ethylphenol. The phenol was synthesized and the phosphate tri-ester formed and given to six birds in five doses of $500 \mathrm{mg}$. $/ \mathrm{kg}$. body weight. All six birds remained well and the ester is considered to be non-toxic.

Other Phenols. - Of the phenols $4 \%$ boil between $228^{\circ}$ and $230^{\circ} \mathrm{C}$. They are a mixture of methylethylphenol, dimethylethylphenol and isopropylphenol. We concentrated these phenols in one fraction and formed the phosphate ester from it. In two experiments 10 birds were given $5 \times 500 \mathrm{mg}$. $/ \mathrm{kg}$. body weight of this phosphate ester. One bird died of atypical symptoms presumed to be due to lympho- matosis but all the other birds remained healthy. We concluded that this phosphate ester is non-toxic. Our findings, with some chemical and physical properties of the pure esters, are summarized in Tables 2 and 3.

\section{Conclusions}

Previous workers have established that the toxicity of commercial samples of tritolyl phosphate (TTP) is due to the presence of phosphate esters containing the ortho-tolyl (ortho-methylphenyl) group. Henschler has claimed that esters which contain only one such group per molecule are the most toxic.

The present series of experiments has shown that even when all ortho cresol is removed from the phenolic starting materials, the resulting TTP is still toxic. Experiments with pure esters of known structure have shown that the toxicity is not due to the presence of dialkyl substituted phenyl groups (even where one alkyl substituent is ortho to the phenolic hydroxyl, as in tri-2:4 and $2: 5$-dimethylphenyl phosphate), since such esters are not toxic in the doses we used.

Mono-ortho ethylphenyl di-para-tolyl phosphate or di-ortho-ethylphenyl mono-para-tolyl phosphate are toxic. As in the case of the ortho-tolyl phosphates, the mixed esters are more toxic than the tri-ester (tri-ortho-ethylphenyl phosphate), the latter being non-toxic to chickens at a dose level of 2,500 $\mathrm{mg} . / \mathrm{kg}$. body weight. A phenolic fraction from which all the ortho-cresol and the ortho-ethylphenol has been removed has produced a TTP of a very low

TABLE 4

TOXICITY TESTS OF NON-TOXIC PLASTICIZER (NTP) IN CHICKENS

\begin{tabular}{|c|c|c|c|c|}
\hline \multirow{2}{*}{$\underset{*}{\text { Buatch }}$} & \multirow{2}{*}{$\begin{array}{l}\text { Number } \\
\text { of } \\
\text { Chickens }\end{array}$} & \multirow{2}{*}{ Dose mg./kg. } & \multicolumn{2}{|c|}{ Neurotoxic Signs } \\
\hline & & & Clinical & Histological \\
\hline $\begin{array}{l}1853 \\
1854 \\
1854 / 1 \\
1854 / 1 \\
1854\end{array}$ & $\begin{array}{c}7 \\
34 \\
6 \\
4 \\
12 \text { in four batches } \\
(4,4,2 \text {, and } 2)\end{array}$ & $\begin{array}{l}5 \times 500 \\
5 \times 500 \\
5 \times 500 \\
5 \times 5,000 \\
4: 1 \times 5,000 \\
4: 1 \times 2,500 \\
2: 1 \times 1,000 \\
2: 1 \times 500\end{array}$ & $\begin{array}{c}5 \text { negative } \\
34 \text { negative } \\
6 \text { negative } \\
4 \text { negative } \\
4 \text { negative } \\
3 \text { negative } \\
2 \text { negative } \\
2 \text { negative }\end{array}$ & $\begin{array}{l}8 \text { negative } \\
2 \text { negative }\end{array}$ \\
\hline 3304 & $\begin{array}{l}28 \\
6\end{array}$ & $\begin{array}{l}5 \times 500 \\
1 \times 1,000 \\
\text { intraperitoneally }\end{array}$ & $\begin{array}{l}3 \text { behaved abnormally but no } \\
\text { specific findings: one of } \\
\text { these had coccidiosis } \\
25 \text { negative } \\
6 \text { negative }\end{array}$ & $\begin{array}{l}2 \text { of the } 3 \text { birds behaving abnormally were } \\
\text { examined histologically-negative: } 3 \text { others } \\
\text { negative }\end{array}$ \\
\hline 3333 & $\begin{array}{l}11 \text { in three batches } \\
(6,3 \text {, and } 2)\end{array}$ & $\begin{array}{l}6: 5 \times 500 \\
3: \quad 1 \times 1,000 \\
2: 5 \times 5,000\end{array}$ & $\begin{array}{l}6 \text { negative } \\
3 \text { negative } \\
2 \text { negative }\end{array}$ & \\
\hline 3334 & $\begin{array}{c}8 \text { in three batches } \\
(3,3 \text {, and } 2)\end{array}$ & $\begin{array}{ll}3: & 5 \times 500 \\
3: & 1 \times 1,000 \\
2: & 5 \times 5,000\end{array}$ & $\begin{array}{l}3 \text { negative } \\
3 \text { negative } \\
2 \text { negative }\end{array}$ & \\
\hline
\end{tabular}

*1853: Phenolic fraction and phosphate ester prepared in laboratory; 1854: Phenolic fraction made on plant, ester made in laboratory 1854/1: A second batch of phenolic fraction made on plant, ester made in laboratory; 3304 : Phenolic fraction and ester made on plant: 3333: Second batch made on plant; 3334: Third batch made on plant.

+ 3wo non-specific deaths. $\$$ ine non-specific death.
+ none

Two non-specific deaths.
Footnote.-Period of observation was 30 days or more in each case. Several chickens were observed for many months after dosing and lack of toxicity was confirmed. 
order of toxicity. This residual toxicity is probably due to the fact that not all the ortho-ethylphenol has been removed. A TTP made from a synthetic mixture of meta-cresol, para-cresol and $2: 4$ and $2: 5$ dimethylphenol proved to be non-toxic. If, in the preparation of trixylenyl phosphate, all orthocresol and all ortho-ethylphenol is removed, the resulting TXP is still slightly toxic. This residual toxicity has now been attributed to the hitherto unsuspected presence of ortho-propylphenol in the raw material, and mixed esters containing the orthopropylphenyl group have, with one exception, also proved to be toxic.

Removal of ortho-cresol and ortho-ethyl and ortho-propyl-phenols from a mixed xylenol fraction has given a phenolic mixture from which a nontoxic phosphate ester (NTP) has been prepared. NTP has been fed to chickens in doses ranging from $1,000 \mathrm{mg}$. $/ \mathrm{kg}$. to $25,000 \mathrm{mg} . / \mathrm{kg}$. body weight, without the appearance of any toxic symptoms (Table 4). Long-term feeding experiments are in progress, and it is apparent that those on very high doses $(5,000$ p.p.m. in the diet) have not thrived as well as the controls and show some changes in the central nervous system which are the subject of further study (Cavanagh, 1960).

Surprisingly tri-para-ethylphenyl phosphate (unlike tri-para-tolyl phosphate) is toxic, in doses as low as $200 \mathrm{mg}$. $/ \mathrm{kg}$. body weight. On the other hand mixed esters containing one or two para-ethylphenyl groups are non-toxic. This finding is so completely at variance with that of the ortho-alkylphenyl esters described above, that it might suggest a different toxic mechanism in the two cases, though there is as yet no evidence, either from macroscopic or microscopic study of the affected chickens, that this is so.

Tri-2-methyl-4-ethylphenyl phosphate, which con- tains para-ethyl and ortho-methyl substituents in the same benzene ring, has been tested and found nontoxic at the $2,500 \mathrm{mg} . / \mathrm{kg}$. level.

The $3: 5$-dimethylphenyl group markedly reduced the toxic effect of the mono-ortho-alkyl groups, thus mono-ortho-tolyl-di-3 : 5-dimethylphenyl phosphate and mono-ortho-ethylphenyl di-3 : 5-dimethylphenyl phosphate are less toxic than other mixed esters containing the ortho-tolyl or the ortho-ethylphenyl group. The effect of the $3: 5$-dimethylphenyl group is strongest in mono-ortho-propylphenyl di-3:5dimethylphenyl phosphate because this compound proved to be non-toxic.

The authors wish to thank the Directors of Coalite and Chemical Products Limited, and Albright and Wilson Limited for their generous support in this research.

\section{REFERENCES}

Aldridge, W. N. (1954). Biochem. J., 56, 185.

Ammon, R. (1933). Pfü̈gers Arch. ges. Physiol., 233, 486.

Barnes, J. M. (1958, 1959, and 1960). Personal communications. Band Denz., F. A. (1953). J. Path. Bact., 65, 597.

Cavanagh, J. B.' (1954). J. Neurol. Neurosurg. Psychiat., 17, 163. Cavanagh, J. B. (1954). J. Neurol. Neuro.

Clough, M., and Cock, A. G. (1957). Nature (Lond.), 179, 1030.

Earl, C. J., and Thompson, R. H. S. (1952). Brit. J. Pharmacol., 7, 685 .

Henschler, D. (1958). Klin. Wschr., 36, 663.

- (1959). Naunyn-Schmiedeberg's Arch. exp. Path. Pharmak. 237, 459.

- , and Bayer, H.-H.(1958). Naunyn-Schmiedeberg's Arch. exp. Path. Pharmak., 233, 512.

Hine, C. H., Dunlap, M. K., Rice, E. G., Coursey, M. M., Gross, R. M., and Anderson, H. H. (1956). J. Pharmacol. exp. Ther., 116, 2,227 .

Hodge, H. C., and Sterner, J. H. (1943). Ibid., 79, 225.

Hodge, H. C., and Sterner, J. H. (1943). R. B. (1944). Brit. J. industr. Med., 1, 227 .

Poirier, L. J., Ayotte, R. A., and Gauthier, C. (1954). Stain Technol., 29, 71 .

Smith, Honor V., and Spalding, J. M. K. (1959). Lancet, 2, 1019.

Smith, M. I., Elvove, E., and Frazier, W. H. (1930). Publ. Hlth Rep. (Wash.), 45, 2509.

Valaer, P. J., Frazer, W. H., and Mallory, G. E. (1930) Ibid., 45,1703 .

Engel, E.W., and Stohlman, E. F. (1932). National Institute of Health Bulletin, No. 160

of Health Bulletin, No. 160. Arch. Neurol. Psychiat. (Chicago), and Lillie,

Steinkopf (1941). Diss: Hamburg.

Susser. M., and Stein, Z. (1957). Brit. $J$. industr. Med., 14, 111

Swank, R. L., and Davenport, H. A. (1935). Stain Technol., 10, 87.

Zeligs, M. A. (1938). J. nerv. ment. Dis., 87, 464. 